\title{
A Systematic Review of Research on Autism Spectrum Disorders in Sub-Saharan Africa
}

\author{
Amina Abubakar, ${ }^{1,2,3}$ Derrick Ssewanyana, ${ }^{1}$ and Charles R. Newton ${ }^{1,2}$ \\ ${ }^{1}$ Kenya Medical Research Institute-Wellcome Trust Collaborative Programme, Kilifi, Kenya \\ ${ }^{2}$ Department of Psychiatry, University of Oxford, Oxford, UK \\ ${ }^{3}$ Department of Public Health, Pwani University, Kilifi, Kenya \\ Correspondence should be addressed to Amina Abubakar; aabubakar@kemri-wellcome.org
}

Received 6 August 2016; Accepted 20 September 2016

Academic Editor: Barbara Picconi

Copyright (C) 2016 Amina Abubakar et al. This is an open access article distributed under the Creative Commons Attribution License, which permits unrestricted use, distribution, and reproduction in any medium, provided the original work is properly cited.

\begin{abstract}
The burden of autism spectrum disorders (ASDs) in sub-Saharan Africa (SSA) is not well known. We carried out a systematic review of the literature to identify published work from SSA. We have systematically searched four databases, namely, Medline, PsycINFO, CINAHL, and Child Development \& Adolescent Studies, through EBSCO and identified studies from across SSA. Based on predefined inclusion criteria, 47 studies were included in this review. Most of the identified studies (74\%) were conducted in only 2 African countries, that is, South Africa and Nigeria. Additionally, most of these studies (83\%) were carried out in the last decade. These studies had four major themes: development of measurement tools of ASD in Africa, examining the prevalence of ASD, identifying risk factors and risk markers, and examining psychosocial issues. We identified only a single population level study aimed at documenting the prevalence of ASD and could not identify a single case-control study aimed at examining a comprehensive set of potential risk factors. All intervention studies were based on very small sample sizes. Put together, our findings suggest that current evidence base is too scanty to provide the required information to plan adequately for effective intervention strategies for children with ASD in Africa.
\end{abstract}

\section{Introduction}

Autism spectrum disorders (ASDs) are a neurodevelopmental syndrome with growing global health concern. This syndrome is characterized by deficits in social and communication skills and restricted and repetitive behaviour; and these adversely impact quality of life of those affected as well as their families [1]. Globally, one in every 160 persons is estimated to live with ASD, contributing to 7.6 million disability life adjusted years [2]. However, this burden is currently underestimated since prevalence of ASD in the African region and other low or middle income regions is still unclear [2-4]. One study, for example, that involved two North African countries documented a high frequency of ASD at $11.5 \%$ and $33.6 \%$ among African children with developmental disorders [5]. Other studies conducted among children of African descent have reported high occurrence of ASD [6-8] although their representativeness is questionable
[9]. Similarly, studies on ASD document a large burden of nonverbal ASD cases (50-71\%) and over 60\% comorbid intellectual disability among African children with ASD [10, 11]. These and other distinctive traits of ASD in Africa such as a potential infectious aetiology, late diagnosis, and poor management $[2,3,12]$ accentuate the need for more research focus and public health response in this region.

Having gone past the prior dialogue questioning the universality of ASD [13], growing interest in ASD in Africa is currently documented by the increasing number of scientific studies on this condition in the continent $[4,9]$. There have been a few reviews synthesizing the data on ASD from Africa [4, 9]; however, most of them were performed years ago, used a single bibliographic search, or did not utilize a systematic review. Although these earlier reviews provide interesting insights, there is a need to update and synthesize the most recent empirical evidence so as to identify research gaps and potential points of interventions. Of major interest 
is a clearer understanding of the current direction of ASD research in Africa (e.g., the focus on risk factors, prevalence, or interventions), identifying where in Africa ASD research is emanating as well as the key findings from ASD research in the African region. This current systematic review builds upon this backdrop by exploring ASD research in the subSaharan African (SSA) region over the past 50 years. We hope that this systematic review will avail relevant evidence to support and guide research, intervention, and policy on ASD, especially in the SSA region.

\section{Methods}

2.1. Search Strategy. Guidelines for preferred reporting items for systematic reviews and meta-analyses (PRISMA) were utilized [58]. We searched four databases, that is, Medline (1935 to June 2016), PsycINFO (1935 to June 2016), CINAHL (1935 to June 2016), and Child Development \& Adolescent Studies (1935 to June 2016), through EBSCO. The search terms used were "Autism" OR "Autistic" OR "Pervasive" AND "Africa”. Our database search was restricted to peer-reviewed articles and excluded dissertations. We further searched the reference lists of retrieved articles as well as the Google Scholar database for other potentially relevant studies that may have been missed from the systematic database search.

2.2. Criteria for Inclusion and Exclusion. We set out the following inclusion criteria:

(1) The study must be an empirical study on ASD conducted among humans.

(2) ASD must be the main condition of study.

(3) The study populations need to be from SSA and the study needs to be carried out in SSA.

We excluded studies that (i) were not empirical, (ii) were conducted in countries other than those from SSA, and (iii) did not consider ASD as the main disorder of interest.

2.3. Data Extraction and Analysis. One data extraction sheet was used to summarize the data in Microsoft Excel spreadsheet (version 2013) on the general characteristics of the studies and their key findings. These characteristics of interest included (i) author, (ii) year of publication, (iii) country where the study was done, (iv) sample description, and (v) key findings. A narrative synthesis was used to summarize the findings of eligible studies included in this systematic review.

\section{Results}

3.1. Summary of Study Characteristics. We identified a total of 341 potentially eligible studies of which 47 fulfilled the criteria. Figure 1 presents the flow chart on the number of identified abstracts, reasons for exclusion, and articles that were further considered. Table 1 presents a summary of the characteristics of the eligible studies and their key findings. These eligible studies were conducted in very few African countries (around ten). Most of these studies were from South Africa $(n=25,51 \%)$ and Nigeria $(n=11,23 \%)$. Most of the studies ( $n=38,83 \%)$ were carried out in the past decade indicating increased interest in the area.

3.2. Screening and Diagnosis of ASD in Africa. There are few studies that have attempted to validate screening and diagnostic measures for use in SSA. A recent study from Uganda adapted and extended the Ten-Question Questionnaire (TQQ) into a 23-item questionnaire and evaluated the sensitivity and specificity of this new tool to identify ASD alongside general "disability" [17]. It was reported that the 23item questionnaire was modestly successful in identifying a subgroup of children at high risk of being diagnosed as having ASD. A study from Tanzania evaluated the potential use of the Childhood Autism Rating Scale to perform a structured observation to diagnose ASD [16]. In this study, the Childhood Autism Rating Scale was culturally adapted for use in Tanzania. Some of the cultural adaptations included ensuring that the play interactions, materials used, and social routines used to probe the child's behaviour were familiar to the children. Following these adaptations, the authors reported excellent discriminative validity and acceptable levels of sensitivity and specificity. Two recent studies in South Africa have also examined and evaluated the cultural adaptability of ASD measures in their context $[14,15]$. The study by Smith and colleagues evaluated the cultural appropriateness of the Autism Diagnostic Observation Schedule-2 (ADOS-2) [15]. Participants were requested to evaluate the cultural appropriateness of the materials and procedures for administering the ADOS. They reported that most of the social interaction demands, materials, and activities were appropriate for use in the urban samples from Cape Town. However, potential linguistic and semantic biases were observed and therefore guidelines for using ADOS in their setting were developed.

3.3. Prevalence of ASD. A few studies have attempted to estimate the burden of ASD in SSA $[17,19]$. However, most of these studies used convenience sampling with data largely from hospital and specialist units for children with special needs. For instance, a study by Lagunju and colleagues [18] recruited 2320 patients at a paediatric neurological clinic. After a systematic screening, 54 of the 2320 patients were diagnosed with ASD, with estimated prevalence of $2.3 \%$. Additionally, it was noted that parents reported a deviation in development at a mean age of 22.1 months, and they received a diagnosis at a mean age of 44.7 months. Among those with ASD, approximately $75.5 \%$ presented with associated neurological comorbidities. Only one community-based study was identified, in which 1169 Ugandan children aged 2-9 years were surveyed in the Kampala District (half urban and half rural) and eight children had a positive diagnosis of ASD. The authors reported unadjusted prevalence for ASD of 6.8/1000 [17]. All the studies reported higher prevalence among boys compared to girls. Bakare et al. [19] in a study from Nigeria reported an ASD ratio of $4: 1$ for boys and girls, respectively.

3.4. Risk Markers and Risk Factors for ASD. We did not identify any case-control study that examined a comprehensive set of risk factors for ASD in SSA. Small studies have identified specific genetic risk markers and nongenetic risk factors for 


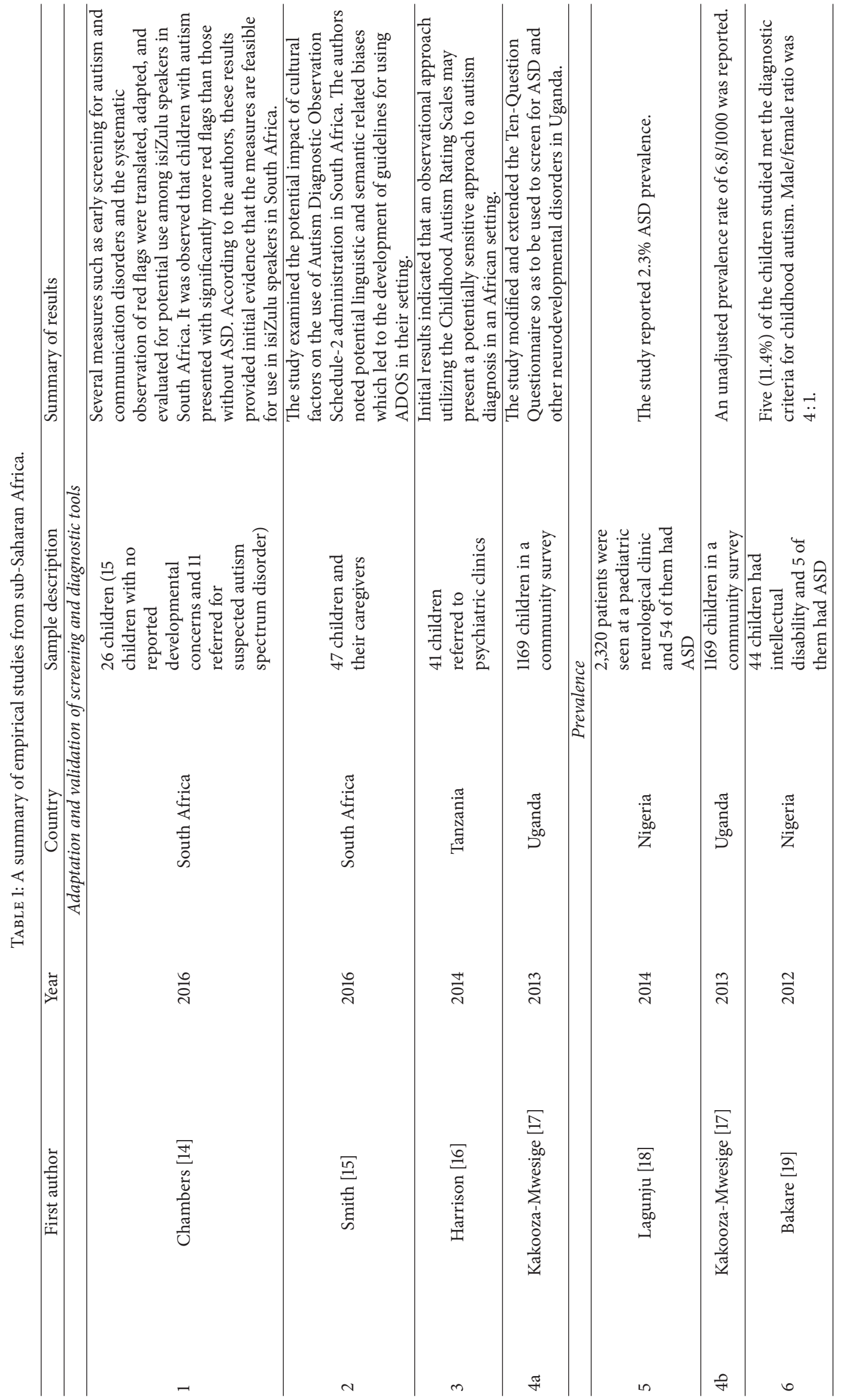




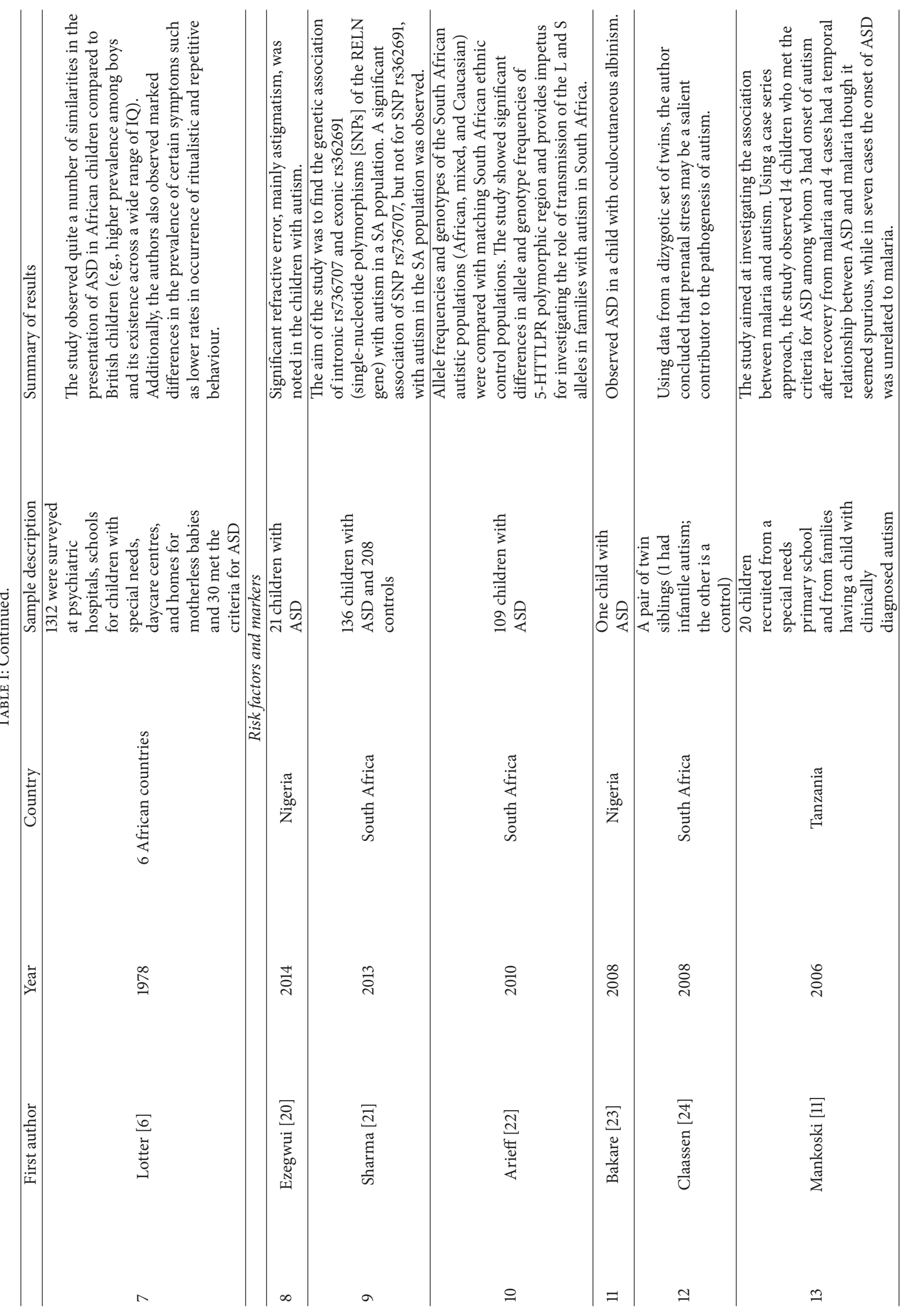




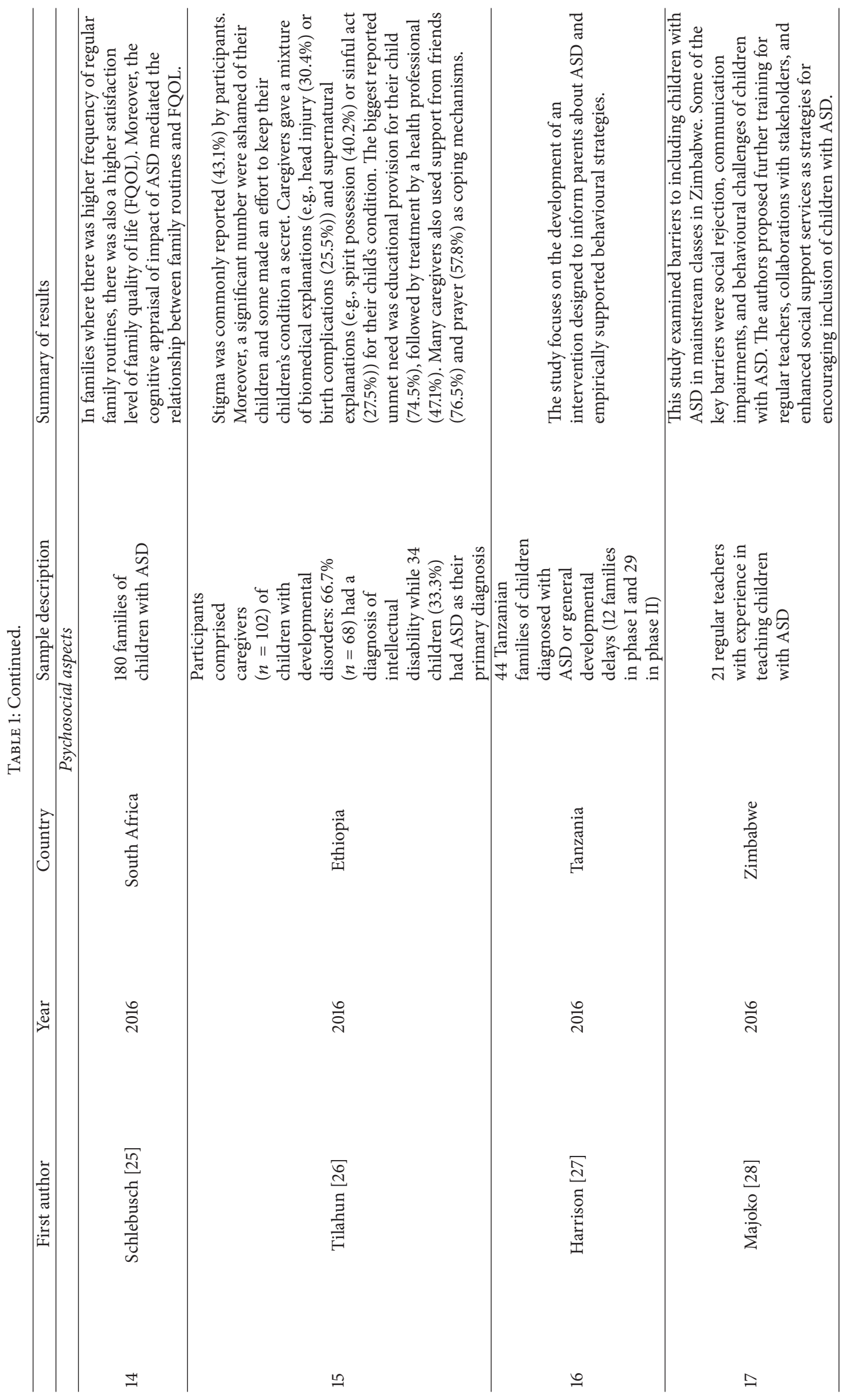




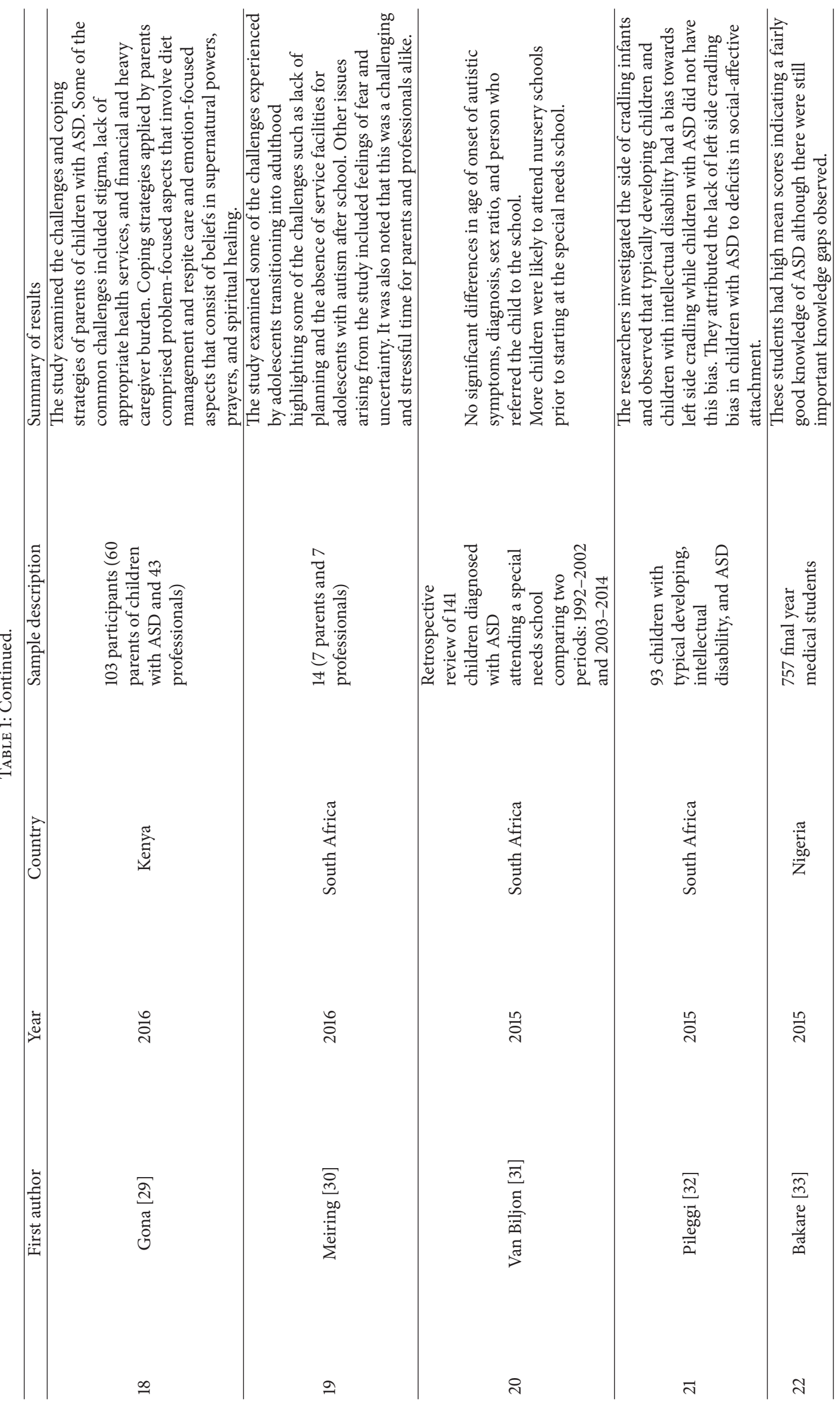




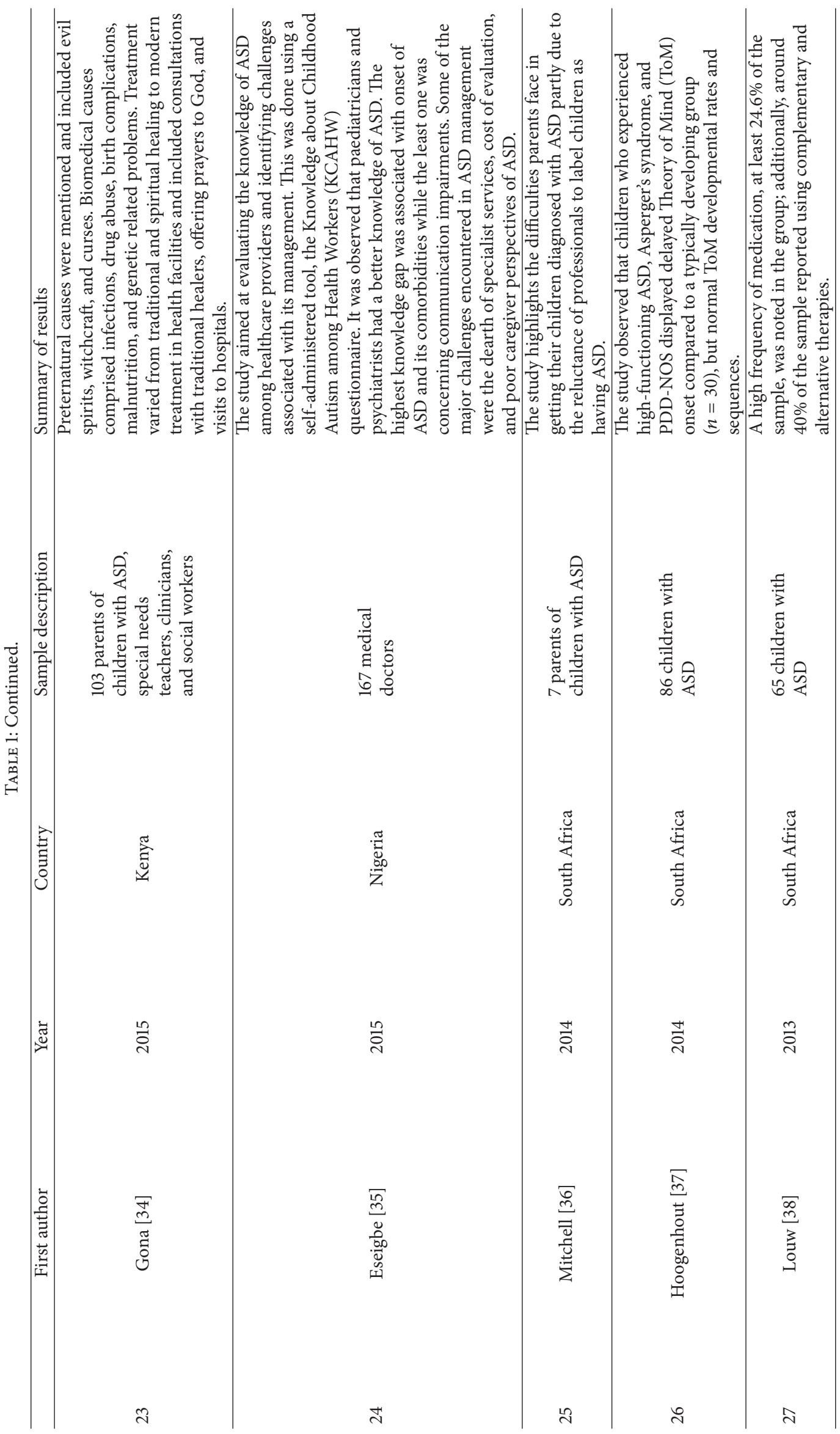




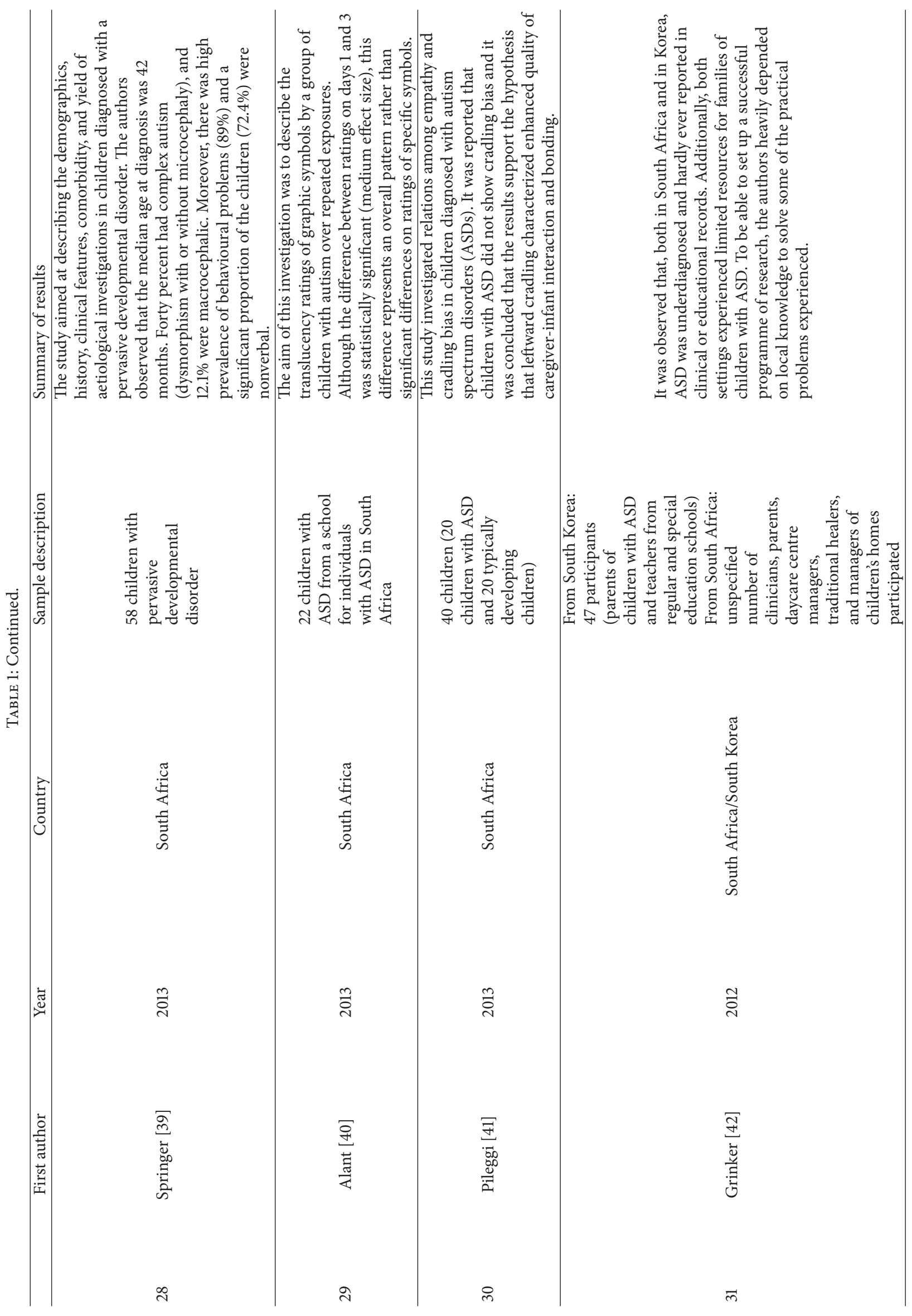




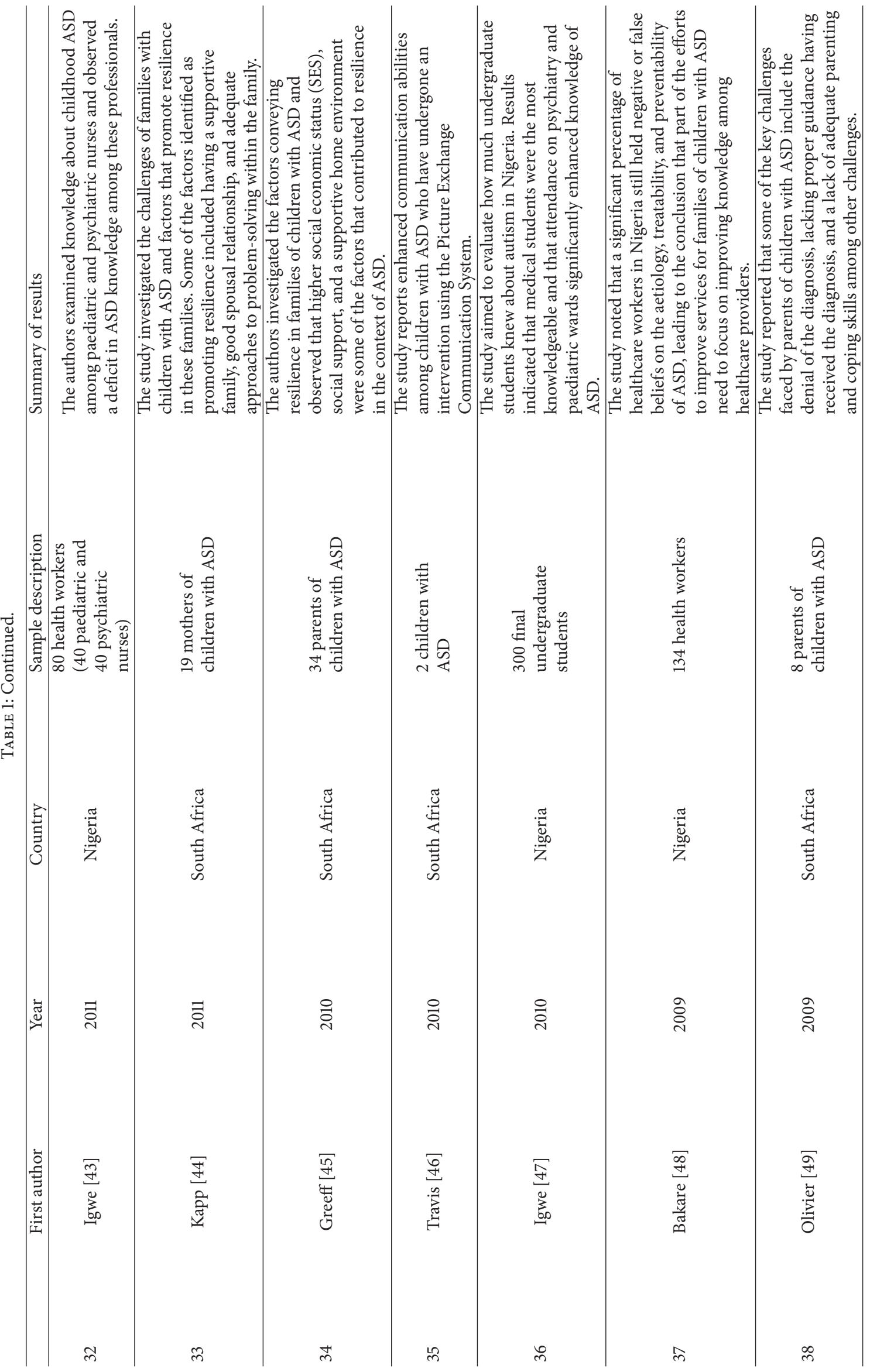




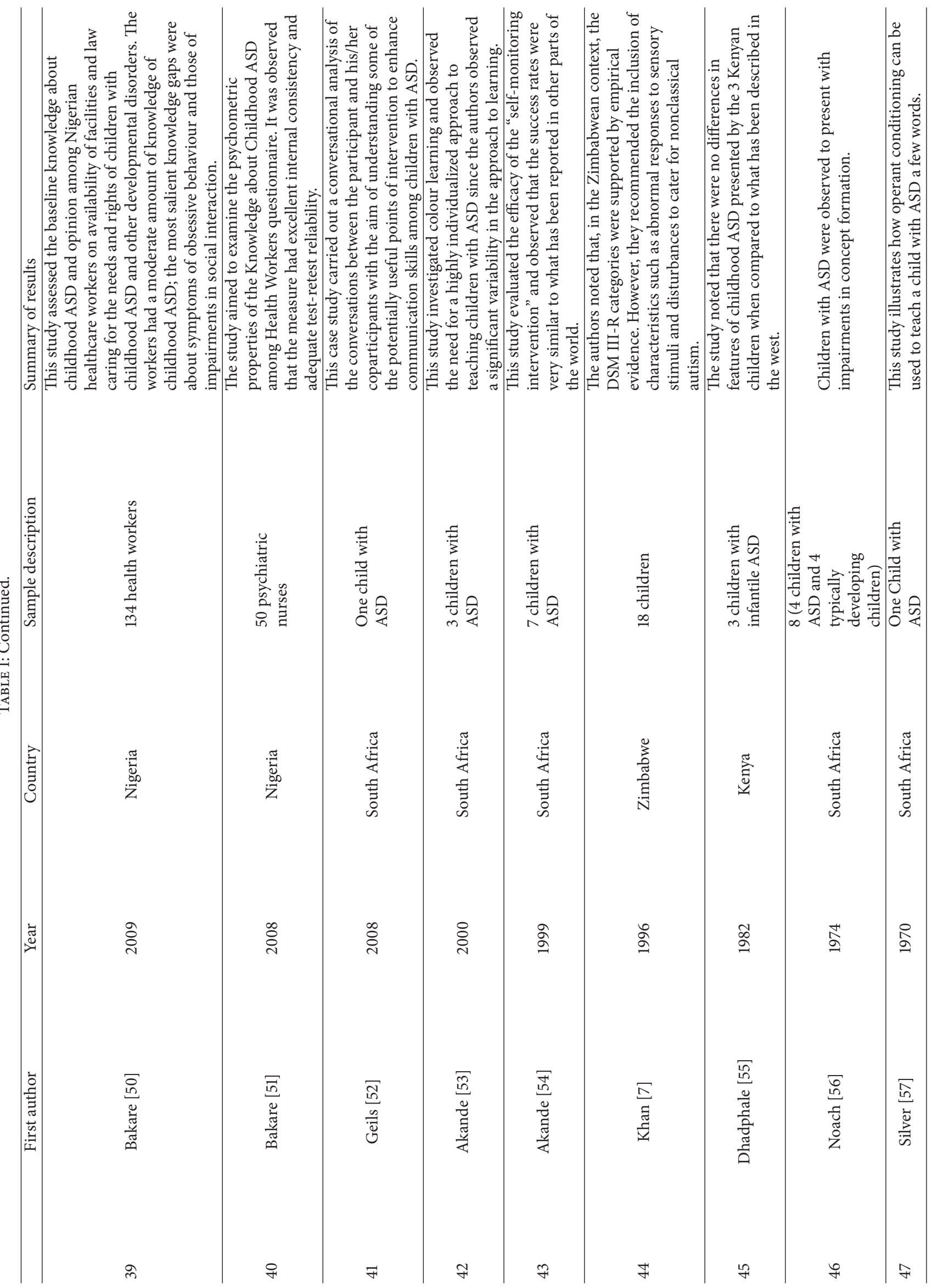




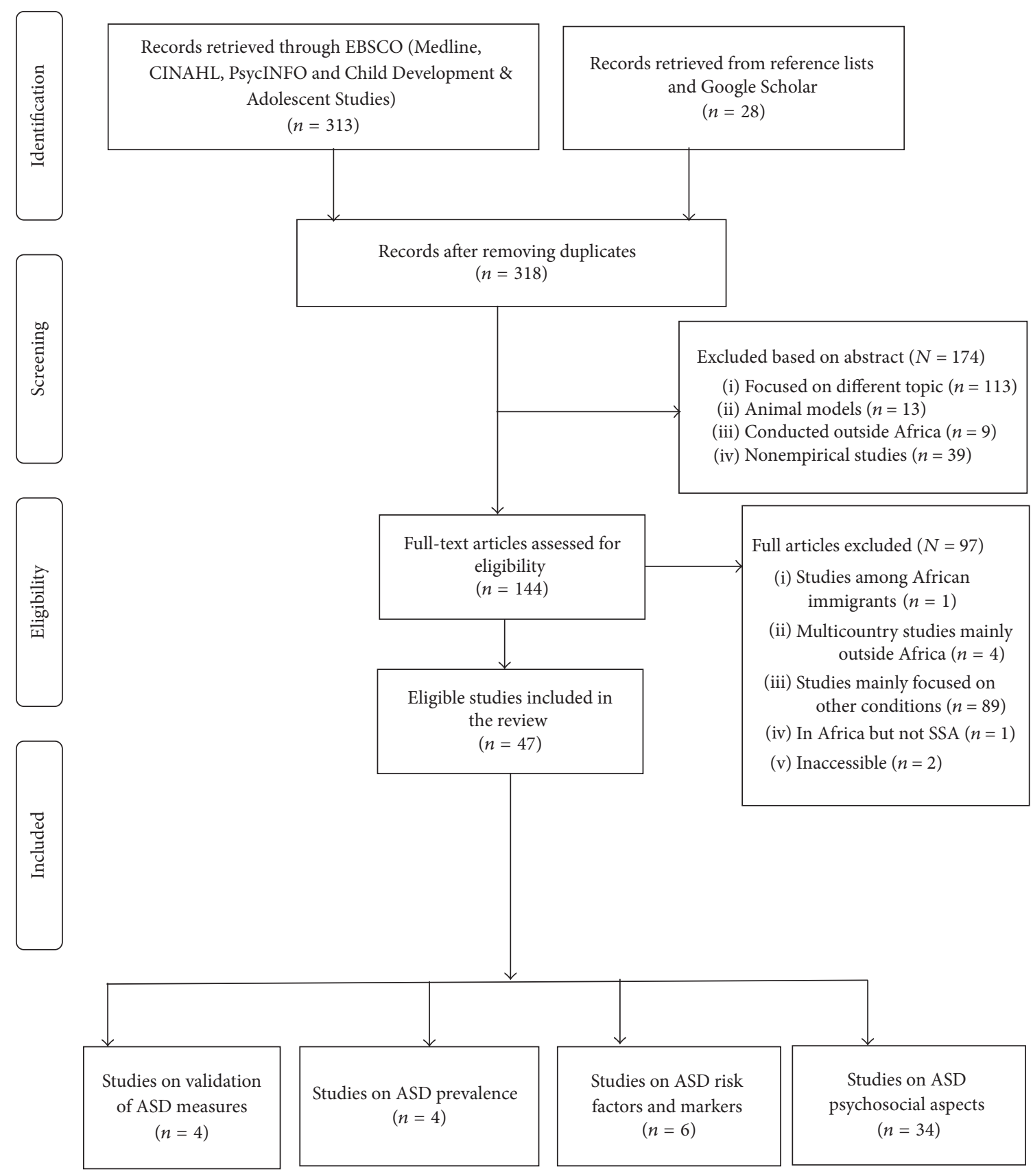

FIGURE 1: A flow diagram of ASD study selection for the systematic review.

ASD [11, 21]. Infectious diseases such as falciparum malaria have been suggested as possible antecedents to ASD [11], but the association has not been established. Of the six studies identified in this category, 4 explored possible genetic and biomedical factors [11, 20-22]. Three of the studies looked at potential genetic markers, the ones by Ezegwui et al. [20], Sharma et al. [21], and Arieff et al. [22]. The studies observed that certain genetic characteristics, for example, allele and genotype frequencies of 5-HTTLPR, were more likely to be associated with an increased risk of ASD. Psychosocial risk factors such as parental stress level have been associated with increased risk of ASD. Unfortunately, the study had a very limited sample size $(n=2)$ compromising the generalisability of these findings [24].

3.5. Psychosocial Aspects of ASD. This category presents the bulk of studies on ASD in Africa. These studies largely examined (a) awareness levels, (b) quality of services provided to children with ASD and caregiver challenges, and (c) sociocultural aspects around ASD, for example, explanatory models on the aetiology of ASD. For instance, most of the healthcare workers in Enugu, Nigeria, had limited knowledge of ASD and perceived the quality of healthcare provided to families of children with ASD as suboptimal 
$[50,51]$. Most of the studies on awareness were carried out in Nigeria by Bakare and colleagues $[33,48,50,51]$. One South African study observed that there were relatively few barriers to participating in ASD research and suggested that most of these barriers were poverty-related [42]. Additionally, a few very-small-scale studies (with participants ranging from 1 to 7 ) have looked at potential intervention strategies to enhance outcomes among children with ASD [59, 60]. For instance, Travis and Geiger investigated the efficacy of the Picture Exchange Communication System (PECS) to improve communication skills in two South African children with ASD [59]. In Tanzania, Harrison and colleagues [27] recently developed an intervention to raise awareness and help caregivers learn some basic behavioural intervention strategies in two phases. In the first phase, 14 caregivers took part in a needs assessment session and an ASD knowledge intervention. In the second phase, 29 caregivers were involved in an intervention focusing on basic behavioural strategies such as parenting skill training, teaching of basic skills (e.g., making eye contact and imitating), and teaching of self-help skills (e.g., feeding). Initial evaluation indicated that despite a few challenges it was feasible to implement the intervention and almost all participating caregivers found it to be useful.

\section{Discussion}

We reviewed the published literature on ASD in sub-Saharan Africa. Our results indicate that there is very limited data from Africa compared to other parts of the world. We identified only a single population level study aimed at documenting the prevalence of ASD in Africa. Additionally, we could not identify a single case-control study aimed at examining a comprehensive set of potential risk factors in Africa. Also, the few intervention studies had very limited sample sizes, were largely cross-sectional, and lack any measurement or evaluation of long-term impact. Put together, our findings suggest that current evidence is too scanty to provide the required information to plan adequately for effective intervention strategies for children with ASD in SSA.

Notable is the fact that most of the identified studies arose from only two African countries, that is, South Africa and Nigeria. The lack of literature from other parts of Africa may be due to several factors. First, there may be a lack of expertise in other African countries; for instance, a recent conference report does document the large difference in number of qualified psychologists and psychiatrists in South Africa compared to other countries that had representatives [61]. Second, this may arise from the lack of resources to carry out research in this area. Another potential explanation is the lack of interest in ASD as a research topic in other parts of Africa. Without any evidence, we can only speculate on the potential reasons for this. However, we feel that the dearth of research from the other African countries reflects the interaction between the first two reasons mentioned earlier. This calls for an urgent need to develop capacity and interest in ASD research in other countries outside SA and Nigeria to expand the evidence base.

An important step towards having an adequate research framework is to have standardized tools for screening and diagnosing. Our research indicates that they are very few tools that have been validated for the African context. The use of tools from other continents does provide challenges for various reasons including methodological and resource availability $[15,61]$. These challenges are the impetus towards the development and validation of tools in the African context. However, some studies [16, 17] present early, yet very crucial steps towards identification of potential screening and diagnostic tools for the African context. The need to invest more into this process cannot be overemphasized given the potential benefit in accessing tools that can contribute towards early identification of children who have ASD.

Our review indicates that a significant proportion of the studies were on psychosocial issues. A major focus of most studies on psychosocial aspects of ASD potentially reflects significant burden on quality of life that African communities are increasingly witnessing and appreciating as resultant from the ASD condition. Thus, there is growing interest in understanding better care and management practices to avert this burden.

4.1. Limitations. We have systematically searched several databases and identified studies from across different settings in Africa. We did not look at grey literature and other more local and regional based databases; consequently, we may have missed out some articles. We, however, did carry out a search of references list to identify more studies. We hope this reduces the potential number of missed studies; however, we cannot completely exclude this possibility.

4.2. Conclusions. Based on our review of published works, it can be said that there is a dearth of scientifically vigorous published work from sub-Saharan Africa making it difficult to estimate the burden of ASD in this population, identify risk factors, or even plan effective intervention strategies.

\section{Competing Interests}

The authors declare that they have no competing interests.

\section{Acknowledgments}

Charles R. Newton is supported by the Ed Scott Foundation and the Wellcome Trust. The paper is published with the permission of the director of KEMRI.

\section{References}

[1] C. Lord, E. H. Cook, B. L. Leventhal, and D. G. Amaral, "Autism spectrum disorders," Neuron, vol. 28, no. 2, pp. 355-363, 2000.

[2] WHO, Autism Spectrum Disorders \& Other Developmental Disorders. From Raising Awareness to Building Capacity, WHO, Geneva, Switzerland, 2013.

[3] C. R. Newton and D. C. Chugani, "The continuing role of ICNA in Africa: how to tackle autism?" Developmental Medicine and Child Neurology, vol. 55, no. 6, pp. 488-489, 2013.

[4] M. O. Bakare and K. M. Munir, "Autism spectrum disorders (ASD) in Africa: a perspective," African Journal of Psychiatry, vol. 14, no. 3, pp. 208-210, 2011. 
[5] A. Seif Eldin, D. Habib, A. Noufal et al., "Use of M-CHAT for a multinational screening of young children with autism in the Arab countries," International Review of Psychiatry, vol. 20, no. 3, pp. 281-289, 2008.

[6] V. Lotter, "Childhood autism in Africa," Journal of Child Psychology and Psychiatry and Allied Disciplines, vol. 19, no. 3, pp. 231-244, 1978.

[7] N. Khan and J. Hombarume, "Levels of autistic behaviour among the mentally handicapped children in Zimbabwe," The Central African Journal of Medicine, vol. 42, no. 2, pp. 36-39, 1996.

[8] M. Barnevik-olsson, C. Gillberg, and E. Fernell, "Prevalence of autism in children born to Somali parents living in Sweden: a brief report," Developmental Medicine and Child Neurology, vol. 50, no. 8, pp. 598-601, 2008.

[9] L. K. Ametepee and M. Chitiyo, "What we know about autism in Africa: a brief research synthesis," The Journal of the International Association of Special Education, vol. 10, no. 1, pp. 11-13, 2009.

[10] A. Belhadj, R. Mrad, and M. B. Halayem, "A clinic and a paraclinic study of Tunisian population of children with autism. About 63 cases," La Tunisie Medicale, vol. 84, no. 12, pp. 763-767, 2006.

[11] R. E. Mankoski, M. Collins, N. K. Ndosi, E. H. Mgalla, V. V. Sarwatt, and S. E. Folstein, "Etiologies of autism in a case-series from Tanzania," Journal of Autism and Developmental Disorders, vol. 36, no. 8, pp. 1039-1051, 2006.

[12] M. O. Bakare, K. M. Munir, and M. A. Bello-Mojeed, "Public health and research funding for childhood neurodevelopmental disorders in Sub-Saharan Africa: a time to balance priorities," Healthcare in Low-resource Settings, vol. 2, no. 1, 2014.

[13] V. D. Sanua, "Is infantile autism a universal phenomenon? An open question," The International Journal of Social Psychiatry, vol. 30, no. 3, pp. 163-177, 1984.

[14] N. J. Chambers, A. M. Wetherby, S. T. Stronach, N. Njongwe, S. Kauchali, and R. R. Grinker, "Early detection of autism spectrum disorder in young isiZulu-speaking children in South Africa," Autism, 2016.

[15] L. Smith, S. Malcolm-Smith, and P. J. de Vries, "Translation and cultural appropriateness of the autism diagnostic observation schedule-2 in afrikaans," Autism, 2016.

[16] A. J. Harrison, E. H. Zimak, S. J. Sheinkopf, K. P. Manji, and E. M. Morrow, "Observation-centered approach to ASD assessment in Tanzania," Intellectual and Developmental Disabilities, vol. 52, no. 5, pp. 330-347, 2014.

[17] A. Kakooza-Mwesige, K. Ssebyala, C. Karamagi et al., "Adaptation of the 'ten questions' to screen for autism and other neurodevelopmental disorders in Uganda," Autism, vol. 18, no. 4, pp. 447-457, 2014.

[18] I. A. Lagunju, T. T. Bella-Awusah, and O. O. Omigbodun, "Autistic disorder in Nigeria: profile and challenges to management," Epilepsy \& Behavior, vol. 39, pp. 126-129, 2014.

[19] M. O. Bakare, P. O. Ebigbo, and V. N. Ubochi, "Prevalence of autism spectrum disorder among Nigerian children with intellectual disability: a stopgap assessment," Journal of Health Care for the Poor and Underserved, vol. 23, no. 2, pp. 513-518, 2012.

[20] I. R. Ezegwui, L. Lawrence, A. E. Aghaji et al., "Refractive errors in children with autism in a developing country," Nigerian Journal of Clinical Practice, vol. 17, no. 4, pp. 467-470, 2014.
[21] J. R. Sharma, Z. Arieff, H. Gameeldien, M. Davids, M. Kaur, and L. Van Der Merwe, "Association analysis of two singlenucleotide polymorphisms of the RELN gene with autism in the South African population," Genetic Testing and Molecular Biomarkers, vol. 17, no. 2, pp. 93-98, 2013.

[22] Z. Arieff, M. Kaur, H. Gameeldien, L. Van Der Merwe, and V. B. Bajic, "5-HTTLPR polymorphism: analysis in South African autistic individuals," Human Biology, vol. 82, no. 3, pp. 291-300, 2010.

[23] M. O. Bakare and N. N. Ikegwuonu, "Childhood autism in a 13 year old boy with oculocutaneous albinism: a case report," Journal of Medical Case Reports, vol. 2, article 56, 2008.

[24] M. Claassen, H. Naudé, E. Pretorius, and M. C. Bosman, “The contribution of prenatal stress to the pathogenesis of autism as a neurobiological developmental disorder: a dizygotic twin study," Early Child Development and Care, vol. 178, no. 5, pp. 487-511, 2008.

[25] L. Schlebusch, A. E. Samuels, and S. Dada, "South African families raising children with autism spectrum disorders: relationship between family routines, cognitive appraisal and family quality of life," Journal of Intellectual Disability Research, vol. 60, no. 5, pp. 412-423, 2016.

[26] D. Tilahun, C. Hanlon, A. Fekadu, B. Tekola, Y. Baheretibeb, and R. A. Hoekstra, "Stigma, explanatory models and unmet needs of caregivers of children with developmental disorders in a low-income African country: a cross-sectional facility-based survey," BMC Health Services Research, vol. 16, no. 1, article 152, 2016.

[27] A. J. Harrison, K. A. Long, K. P. Manji, and K. K. Blane, "Development of a brief intervention to improve knowledge of autism and behavioral strategies among parents in Tanzania," Intellectual and Developmental Disabilities, vol. 54, no. 3, pp. 187-201, 2016.

[28] T. Majoko, "Inclusion of children with autism spectrum disorders: listening and hearing to voices from the grassroots," Journal of Autism and Developmental Disorders, vol. 46, no. 4, pp. 1429-1440, 2016.

[29] J. Gona, C. Newton, K. Rimba et al., "Challenges and coping strategies of parents of children with autism on the Kenyan coast," Rural and Remote Health, vol. 16, no. 3517, 2016.

[30] M. Meiring, J. Seabi, Z. Amod, A. Vorster, and A. Kern, "Transition for adolescents with autism spectrum disorder: South African parent and professional perspectives," Frontiers in Psychiatry, vol. 7, article 39, 2016.

[31] S. Van Biljon, A. Kritzinger, and S. Geertsema, "A retrospective case report on demographic changes of learners at a school for children with Autism Spectrum Disorder in the Gauteng Province," South African Journal of Childhood Education, vol. 5, no. 1, pp. 1-26, 2015.

[32] L.-A. Pileggi, S. Malcolm-Smith, and M. Solms, "Investigating the role of social-affective attachment processes in cradling bias: the absence of cradling bias in children with Autism Spectrum Disorders," Laterality, vol. 20, no. 2, pp. 154-170, 2015.

[33] M. O. Bakare, M. F. Tunde-Ayinmode, A. O. Adewuya et al., "Recognition of Autism Spectrum Disorder (ASD) symptoms and knowledge about some other aspects of ASD among final year medical students in Nigeria, Sub-Saharan Africa," $B M C$ Research Notes, vol. 8, no. 1, article 454, 2015.

[34] J. K. Gona, C. R. Newton, K. Rimba et al., "Parents' and professionals' perceptions on causes and treatment options for Autism Spectrum Disorders (ASD) in a multicultural context 
on the Kenyan Coast," PLoS ONE, vol. 10, no. 8, Article ID 0132729, 2015.

[35] E. E. Eseigbe, F. T. Nuhu, T. L. Sheikh, P. Eseigbe, K. A. Sanni, and V. O. Olisah, "Knowledge of childhood autism and challenges of management among medical doctors in Kaduna State, Northwest Nigeria," Autism Research and Treatment, vol. 2015, Article ID 892301, 6 pages, 2015.

[36] C. Mitchell and N. Holdt, "The search for a timely diagnosis: parents' experiences of their child being diagnosed with an Autistic Spectrum Disorder," Journal of Child \& Adolescent Mental Health, vol. 26, no. 1, pp. 49-62, 2014.

[37] M. Hoogenhout and S. Malcolm-Smith, "Theory of mind in autism spectrum disorder: does DSM classification predict development?" Research in Autism Spectrum Disorders, vol. 8, no. 6, pp. 597-607, 2014.

[38] K.-A. Louw, J. Bentley, K. Sorsdahl, and C. M. Adnams, "Prevalence and patterns of medication use in children and adolescents with autism spectrum disorders in the Western Cape, South Africa," Journal of Child and Adolescent Mental Health, vol. 25, no. 1, pp. 69-79, 2013.

[39] P. E. Springer, R. van Toorn, B. Laughton, and M. Kidd, "Characteristics of children with pervasive developmental disorders attending a developmental clinic in the Western Cape Province, South Africa," South African Journal of Child Health, vol. 7, no. 3, pp. 95-99, 2013.

[40] E. Alant, W. Zheng, M. Harty, and L. Lloyd, "Translucency ratings of blissymbols over repeated exposures by children with Autism," AAC: Augmentative and Alternative Communication, vol. 29, no. 3, pp. 272-283, 2013.

[41] L.-A. Pileggi, S. Malcolm-Smith, M. Hoogenhout, K. G. F. Thomas, and M. Solms, "Cradling bias is absent in children with autism spectrum disorders," Journal of Child and Adolescent Mental Health, vol. 25, no. 1, pp. 55-60, 2013.

[42] R. R. Grinker, N. Chambers, N. Njongwe et al., "'Communities' in community engagement: lessons learned from autism research in South Korea and South Africa," Autism Research, vol. 5, no. 3, pp. 201-210, 2012.

[43] M. N. Igwe, A. C. Ahanotu, M. O. Bakare, J. U. Achor, and C. Igwe, "Assessment of knowledge about childhood autism among paediatric and psychiatric nurses in Ebonyi state, Nigeria," Child and Adolescent Psychiatry and Mental Health, vol. 5, no. 1, article 1, 2011.

[44] L. Kapp and O. Brown, "Resilience in families adapting to Autism Spectrum Disorder," Journal of Psychology in Africa, vol. 21, no. 3, pp. 459-464, 2011.

[45] A. P. Greeff and K.-J. Van der Walt, "Resilience in families with an autistic child," Journal of Pediatric, Maternal \& Family HealthChiropractic, vol. 45, no. 3, p. 347, 2010.

[46] J. Travis and M. Geiger, "The effectiveness of the picture exchange communication system (PECS) for children with autism spectrum disorder (ASD): a South African pilot study," Child Language Teaching and Therapy, vol. 26, no. 1, pp. 39-59, 2010, Erratum to Child Language Teaching and Therapy, vol. 26, no. 3, pp. 383-384, 2010.

[47] M. N. Igwe, M. O. Bakare, A. O. Agomoh, G. M. Onyeama, and K. O. Okonkwo, "Factors influencing knowledge about childhood autism among final year undergraduate medical, nursing and psychology students of University of Nigeria, Enugu State, Nigeria," Italian Journal of Pediatrics, vol. 36, article 44, 2010.

[48] M. O. Bakare, A. O. Agomoh, P. O. Ebigbo et al., "Etiological explanation, treatability and preventability of childhood autism: a survey of Nigerian healthcare workers' opinion," Annals of General Psychiatry, vol. 8, article 6, 2009.

[49] M. A. Olivier and A. D. A. Hing, "Autistic Spectrum Disorder (ASD): parental challenges and strategies," Vulnerable Children and Youth Studies, vol. 4, no. 1, pp. 58-66, 2009.

[50] M. O. Bakare, P. O. Ebigbo, A. O. Agomoh et al., "Knowledge about childhood autism and opinion among healthcare workers on availability of facilities and law caring for the needs and rights of children with childhood autism and other developmental disorders in Nigeria," BMC Pediatrics, vol. 9, no. 1, article $12,2009$.

[51] M. O. Bakare, P. O. Ebigbo, A. O. Agomoh, and N. C. Menkiti, "Knowledge about childhood autism among health workers (KCAHW) questionnaire: description, reliability and internal consistency," Clinical Practice and Epidemiology in Mental Health, vol. 4, article 17, 2008.

[52] C. Geils and J. Knoetze, "Conversations with Barney: a conversation analysis of interactions with a child with autism," South African Journal of Psychology, vol. 38, no. 1, pp. 200-224, 2008.

[53] A. Akande, "Assessing color identification in children with autism," Early Child Development and Care, vol. 164, no. 1, pp. 95-104, 2000.

[54] A. Akande, "Autism - a case in early childhood: a South African investigation," Early Child Development and Care, vol. 155, no. 1, pp. 71-78, 1999.

[55] M. Dhadphale, M. G. Lukwago, and M. Gajjar, "Infantile autism in Kenya," The Indian Journal of Pediatrics, vol. 49, no. 1, pp. 145148, 1982.

[56] M. Noach, "Concept formation in the speaking autistic child," International Journal of Mental Health, vol. 3, no. 1, pp. 100-109, 1974.

[57] E. B. Silver, "Operant conditioning of speech sounds in an autistic child," Journal of Behavioural Science, pp. 3-12, 1970.

[58] D. Moher, A. Liberati, J. Tetzlaff, D. G. Altman, and The PRISMA Group, "Preferred reporting items for systematic reviews and meta-analyses: the PRISMA statement," Annals of Internal Medicine, vol. 151, no. 4, pp. 264-269, 2009.

[59] J. Travis and M. Geiger, "The effectiveness of the Picture Exchange Communication System (PECS) for children with autism spectrum disorder (ASD): a South African pilot study," Child Language Teaching and Therapy, vol. 26, no. 1, pp. 39-59, 2010.

[60] J. K. Gona, C. R. Newton, S. Hartley, and K. Bunning, "A home-based intervention using augmentative and alternative communication (AAC) techniques in rural Kenya: what are the caregivers' experiences?" Child: Care, Health and Development, vol. 40, no. 1, pp. 29-41, 2014.

[61] K. Ruparelia, A. Abubakar, E. Badoe et al., "Autism spectrum disorders in Africa: current challenges in identification, assessment, and treatment: a report on the international child neurology association meeting on ASD in Africa, Ghana, April 3-5, 2014," Journal of Child Neurology, vol. 31, no. 8, pp. 10181026, 2016. 


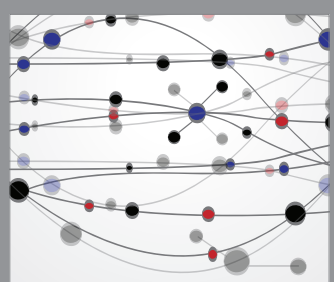

The Scientific World Journal
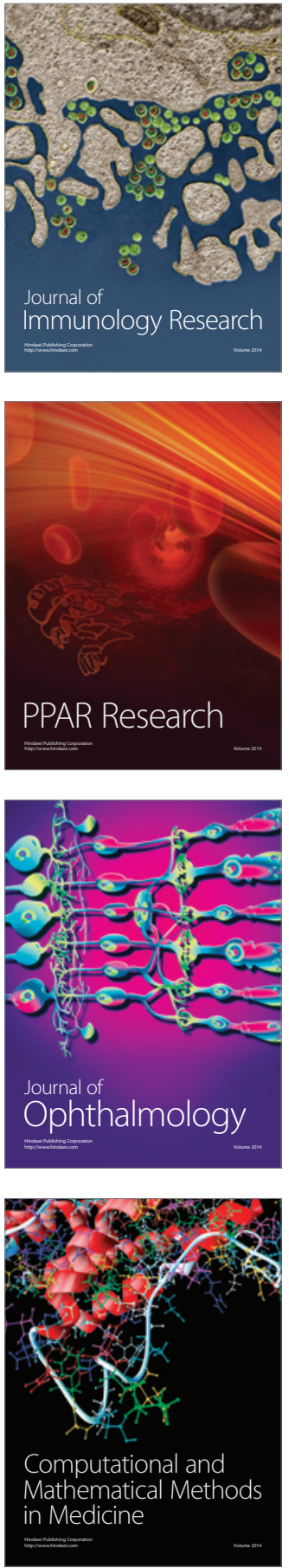

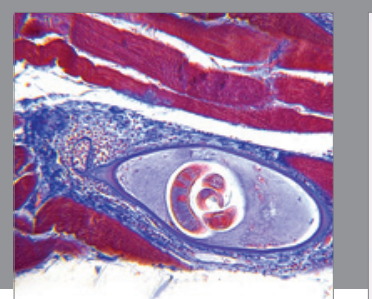

Gastroenterology Research and Practice

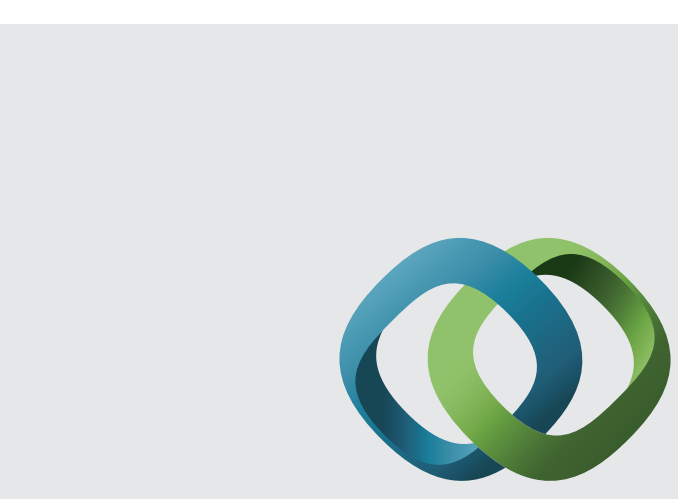

\section{Hindawi}

Submit your manuscripts at

http://www.hindawi.com
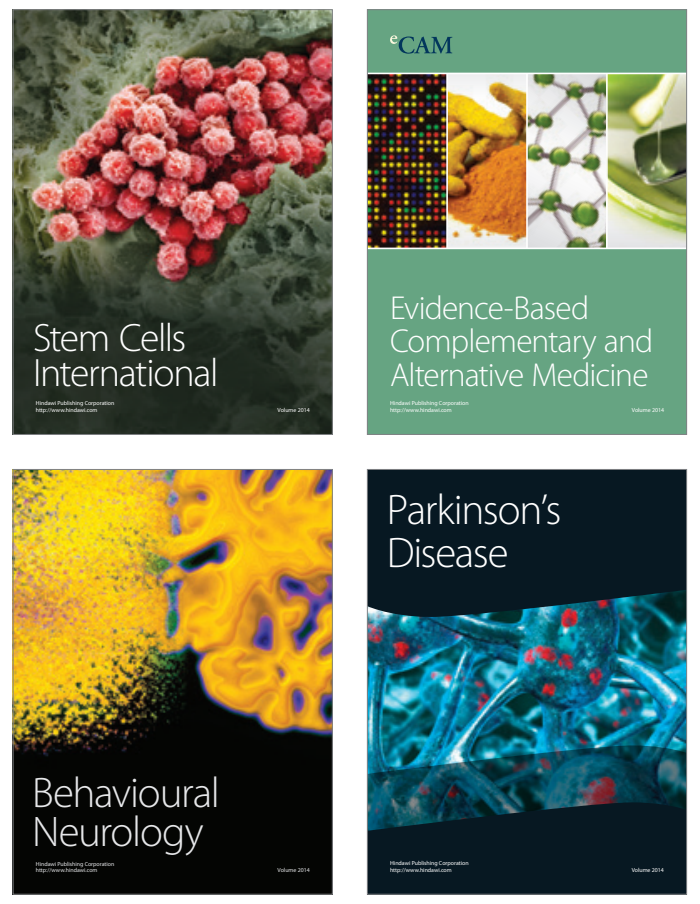
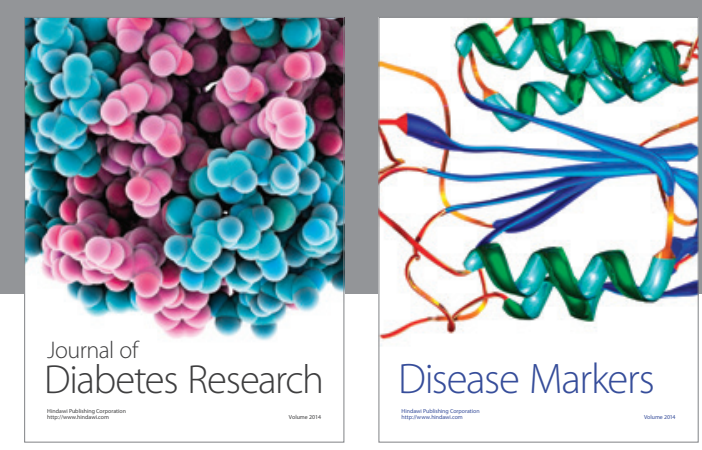

Disease Markers
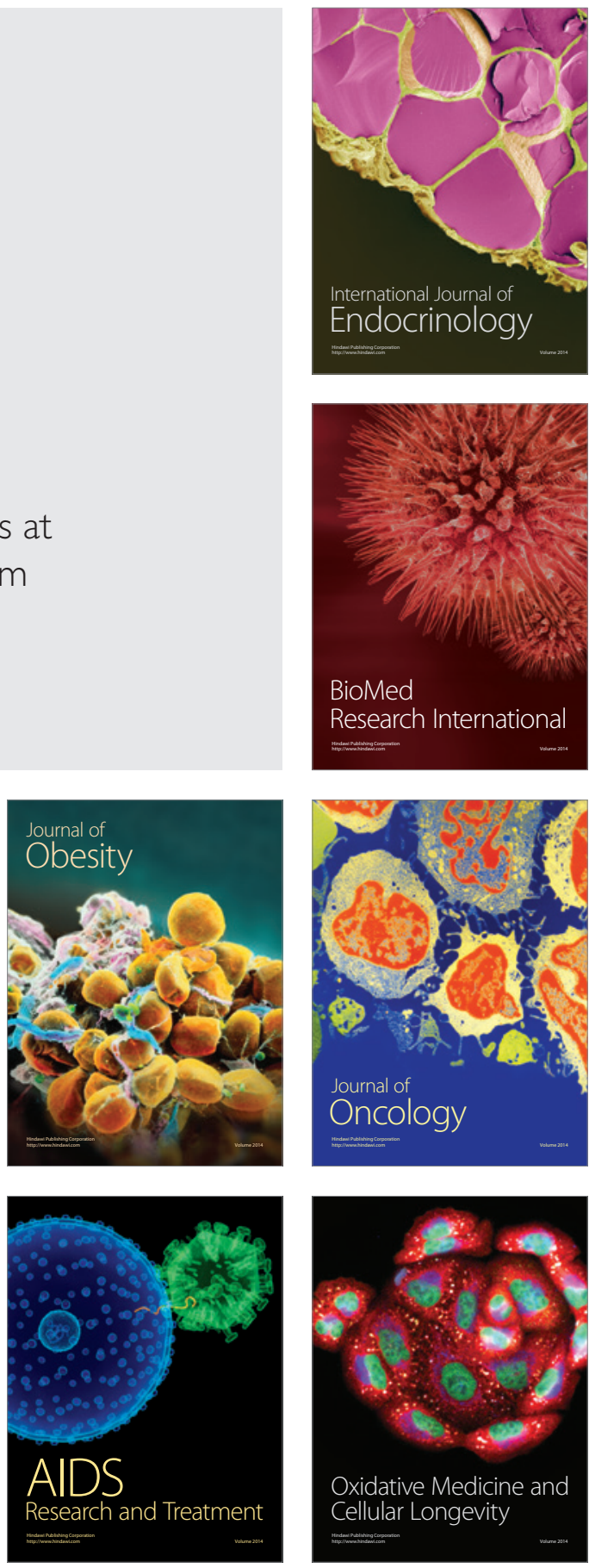